\title{
La Revolución Bolchevique y el Movimiento de Izquierda Revolucionaria (MIR) chileno (1965-1973). Adhesiones y distancias ${ }^{1}$
}

\author{
Bolshevik revolution and the Chilean Movimiento de \\ Izquierda Revolucionaria (MIR) of Chile (1965-1973). \\ Accessions and distances
}

\author{
Igor Goicovic Donoso \\ Universidad de Santiago de Chile \\ (Chile) \\ igor.goicovic@usach.cl
}

\section{Resumen}

El Movimiento de Izquierda Revolucionaria (MIR), de Chile, fundado en 1965, se convirtió entre las décadas de 1960 y 1980, en la principal organización de la izquierda armada del país. Su acervo ideológico fue heterogéneo, en especial en su fase de constitución (1965-1967), a la cual concurrieron organizaciones provenientes de diferentes orientaciones teóricas. No obstante lo anterior, predominaron en sus adhesiones tempranas y en la dirección que asumió el nuevo referente las tesis de Lenin sobre el partido de vanguardia y las tesis de la Revolución Cubana sobre la centralidad de la lucha armada en la toma del poder.

En este artículo nos proponemos conocer las condiciones históricas en las cuales surgió y se desarrolló el MIR chileno y analizar las claves ideológicas que configuraron su entramado teórico. Nos interesa establecer el alcance y los límites que tuvo al interior del MIR el modelo estratégico bolchevique y, a la vez, reconocer la preeminencia que adquirió la Revolución Cubana.

Palabras Clave: Revolución - Bolcheviques - MIR - Chile

1. Este artículo forma parte de los proyectos de investigación Transiciones a la democracia en el sur de Europa y en América Latina: España, Portugal, Argentina y Chile, HAR2015-63657-P (MINECO-España) e Izquierdas latinoamericanas, Grupo de Trabajo CLACSO. 


\begin{abstract}
The Chilean Movimiento de Izquierda Revolucionaria (MIR) founded in 1965, became the main left armed organization of the country between the 1960s and 1980s. Especially in its constitutional phase (19651967), its ideological heritage was heterogeneous, to which attended various organizations from different theoretical orientations. Nevertheless, in its early adherences and in the direction assumed by the new referent, Lenin's theses on the avant-garde party and the theses of the Cuban Revolution on the centrality of the armed struggle in the seizure of power prevailed.

In this article, we propose to grasp the historical conditions in which the MIR emerged and developed and to analyze the ideological keys that shaped its theoretical framework. We are interested in establishing the scope and limits that the Bolshevik strategic model had within the MIR and, at the same time, recognizing the pre-eminence that the Cuban Revolution acquired.
\end{abstract}

Key Words: Revolution - Bolshevik - MIR - Chile

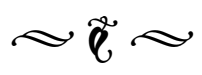

\section{Introducción}

La génesis del movimiento obrero y popular en Chile se encuentra hacia fines del siglo XIX. Sus primeras expresiones correspondieron a las sociedades en resistencia organizadas en los centros urbanos de Santiago y Valparaíso, a las cuales se unieron las mancomunales obreras constituidas en los cantones salitreros de Tarapacá y Antofagasta. ${ }^{2}$ Más tarde, en

2. La bibliografía sobre esta materia es muy amplia, Entre los trabajos recientes de mayor relevancia cabe destacar los siguientes: PINTO, Julio, Trabajos y rebeldías en la pampa salitrera, Ediciones Universidad de Santigo de Chile, Santiago de Chile, 2012; GREZ, Sergio, Historia del comunismo en Chile. La era de Recabarren (1912-1924), LOM Ediciones, 2011; GREZ, Sergio, Los anarquistas y el movimiento obrero: La alborada de la idea en Chile, 1893-1915, LOM Ediciones, Santiago de Chile, 2007; DESHAZO, Peter, Trabajadores urbanos y sindicatos en Chile: 1902-1927, Centro de Investigaciones Diego Barros Arana - DIBAM, Santiago de Chile, 2007 y ARTAZA, Pablo, Movimiento social y politización popular en Tarapacá: 1900-1912, Ediciones Escaparate, Santiago de Chile, 2006.

80
1912, se formó el primer partido político, el Partido Obrero Socialista (en adelante, POS), que adscribió de manera explícita al marxismo en cuanto doctrina y guía para la acción política. ${ }^{3}$ Su proyecto político apuntaba a la abolición del régimen capitalista y a la construcción del socialismo, mientras que su principal líder, el obrero tipógrafo Luis Emilio Recabarren, le imprimió un sello clasista, popular e internacionalista que favoreció su rápido crecimiento. ${ }^{4}$ Concordante con esto, el periódico del POS, El Despertar de los Trabajadores, fundado en 1912, no sólo daba cuenta de las profundas inequidades del sistema capitalista, sino que también abría sus páginas a las luchas del movimiento obrero tanto en Chile, como a nivel internacional. No es extraño, por lo tanto, que la Revolución

3. Al respecto ver, GREZ, Sergio, Historia del comunismo en Chile..., Op. Cit., pp. 23-36.

4. PINTO, Julio, Luis Emilio Recabarren. Una biografía histórica, LOM Ediciones, Santiago de Chile, 2013, pp. 150-201. 
Bolchevique haya impactado profundamente en sus páginas y que, al calor de su influencia, los socialistas chilenos hayan girado hacia el comunismo.

En 1922, Luis Emilio Recabarren visitó Rusia, en el marco de la realización del Cuarto Congreso de la Internacional Comunista. Sus impresiones respecto del proceso revolucionario ruso quedaron registradas en el folleto La Rusia obrera y campesina (1923). En ese documento se puede reconocer la evidente adscripción del líder obrero al proyecto revolucionario liderado por Lenin. ${ }^{5}$ No puede sorprender, por lo tanto, que el POS, durante su III Congreso General (enero de 1922), adscribiera a la III Internacional y, en consonancia con ello, cambiara su nombre por el de Partido Comunista de Chile (en adelante, $\mathrm{PCCh}){ }^{6}$

Tras la muerte de Recabarren, en 1924, el PCCh se adhirió de forma cada vez más estricta a las orientaciones políticas que la III Internacional elaboraba para las organizaciones revolucionarias a escala global. ${ }^{7}$ Esto, junto a la política represiva adoptada por la dictadura de Carlos Ibáñez del Campo (1927-1931), precipitó fuertes disputas internas en el campo del movimiento obrero. Así, la emergente crítica al Stalinismo y al carácter autoritario y centralizado del régimen comunista en la Unión de Repúblicas Socialistas Soviéticas

5. RECABARREN Luis Emilio, La Rusia obreray campesina, La Federación Obrera, Santiago de Chile, 1923.

6. GREZ, Sergio, Historia del comunismo en Chile...,Op. Cit., pp. 153-159.

7. RAMIREZ, Hernán, Origen y formación del Partido Comunista de Chile, Editorial Progreso, Moscú, 1984, pp. 217-280.
(URSS), llevó a algunos intelectuales y dirigentes obreros a fundar en 1933 el Partido Socialista de Chile (en adelante, PSCh), que sin proclamarse leninista, reconoció en la Revolución Bolchevique de 1917, un hito fundamental en la luchas del proletariado por su emancipación. Se trataba, a juicio de los socialistas de los años treinta, de una "revolución traicionada" por el Stalinismo. ${ }^{8}$

Entre la década de 1930 y 1940, comunistas y socialistas, junto a la principal central obrera de la época, la Confederación de Trabajadores de Chile (en adelante, CTCH) fundada en 1936, y el centrista Partido Radical (PR), asumieron la estrategia frentepopulista elaborada por la III Internacional (1935). Esta alianza llegó al poder en 1938, bajo la conducción del dirigente radical Pedro Aguirre Cerda y, bajo diferentes denominaciones, se mantuvo en el poder hasta 1947 (gobierno de Gabriel González Videla). ${ }^{9}$ Ese año, la administración de Gabriel González Videla, fuertemente presionada por EE.UU., en los albores de la Guerra Fría, rompió con los comunistas chilenos e inició una sistemática represión de los mismos. No obstante lo anterior, los comunistas chilenos mantuvieron su adscripción a la institucionalidad democrática y renunciaron, en la práctica, a la insurrección bolchevique como estrategia de lucha. ${ }^{10}$

Las tesis de Lenin, respecto del asalto violento al poder, como instrumento fundamental en

8. JOBET, Julio Cesar, El partido Socialista de Chile, T. I, Editorial PLA, Santiago de Chile, 1971, pp. 21-25.

9. MILOS, Pedro, Frente Popular en Chile: Su configuración, 1935-1938, LOM Ediciones, Santiago de Chile, 2008.

10. FURCI, Carmelo, El Partido Comunista de Chile y la vía al socialismo, Ariadna Editores, Santiago de Chile, 2008, pp. 66-78. 
la lucha por la construcción del socialismo, sólo fueron reivindicadas por una franja reducida de trabajadores e intelectuales que se nuclearon en organizaciones políticas con escaso apoyo social. No obstante, el ascenso experimentado por las luchas sociales y políticas, desde comienzos de la década de 1950 volvió a instalar estos contenidos en la discusión pública de la izquierda.

\section{Ascenso y radicalización del movimiento popular en Chile}

A comienzos de la década de 1950 los efectos derivados del proceso de modernización económica iniciado a fines del siglo XIX ya eran evidentes. La Corporación de Fomento de la Producción (en adelante, CORFO), un organismo creado por el Estado en 1939, generó las condiciones de infraestructura necesarias (hidroeléctricas, petrolíferas, siderúrgicas, viales, etc.), para profundizar la industrialización del país. ${ }^{11}$ Los soportes en infraestructura, equipamiento, recursos financieros y asesorías técnicas que el Estado, a través de la CORFO, desplegó en este período, favorecieron el desarrollo del sector industrial, en particular, la industria ligera (alimentaria, textil, cuero y calzado). Pero, ya desde comienzos de la década de 1950, es posible observar una ampliación del mercado interno y un desarrollo relativo de las capas medias, con lo cual este mercado se diversificó, dando origen a la industria de bienes intermedios (línea blanca, automotriz, electrónica) y estimulando el desarrollo de la industria metalmecánica y de la construcción.

11. MELLER, Patricio, Un siglo de economía politica chilena (1890-1990), Editorial Andrés Bello, Santiago de Chile, 1998, pp. 47-60.
Por su parte la gran minería del cobre (Chuquicamata, El Teniente y El Salvador), que desde la década de 1920 comenzó a relevar al salitre como soporte principal de la economía del país, aportó importantes recursos al Estado por concepto de tributación. ${ }^{12}$ A su vez, los mayores niveles de contribuciones impositivas y la creciente preocupación del Estado por la condición de las clases populares estimularon la inversión pública en educación. Lo anterior conllevó un crecimiento sostenido de las coberturas educacionales, especialmente en enseñanza primaria y secundaria (industrial), y una diversificación de la oferta universitaria. A su vez, la ampliación de las coberturas educacionales, unida a la oferta laboral del sector industrial, incentivaron los procesos migratorios desde las áreas rurales hacia los centros urbanos. De esta manera, las grandes ciudades del país: Santiago, Valparaíso, Concepción, en las cuales se concentraba la oferta manufacturera y educacional, comenzaron a convocar a crecientes contingentes de trabajadores rurales. ${ }^{13}$

Pero las ciudades del país no estaban preparadas para recibir este creciente y masivo proceso migratorio. Los déficits en infraestructura

12. Ídem, p. 33.

13. A comienzos del siglo XX (1907) la población urbana en Chile representaba un $43 \%$ del total de la población. Al cerrarse la centuria (1992), el porcentaje de población urbana llegaba al 83\% sobre el total. El tema de las migraciones campo-ciudad ha sido abordado, especialmente por la sociología y la demografía. La historia no ha contribuido significativamente al análisis del fenómeno. Ver, al respecto, MUNDLAK, Yair, "Migración del campo a la ciudad: Análisis empírico basado en datos rurales", en Cuadernos de Economía, Santiago de Chile, 1978, V. 15, No 45, pp. 143-181. y ZEMELMAN, Hugo, El migrante rural, ICIRA, Santiago de Chile, 1971. 
y equipamiento urbano, así como las insuficiencias de la política pública en materia de vivienda, hicieron muy difícil el proceso de asentamiento de los inmigrantes y complejizaron sus estrategias de subsistencia. En las periferias urbanas se fue arraigando la pobreza y junto con ello se fue constituyendo un nuevo actor social, el poblador. Este sujeto social, devenido en actor colectivo, comenzó a protagonizar una serie de ocupaciones ilegales de terrenos (tomas), que ampliaron el campo de acción político de los partidos de izquierda. ${ }^{14}$

En este contexto las derrotas políticas experimentadas por el movimiento popular en el ciclo 1947-1949, fueron gestando nuevos aprendizajes que instalaron entre la dirigencia obrera la necesidad de un proyecto clasista y revolucionario. ${ }^{15}$ Este proceso se inauguró a comienzos de la década de 1950 y tuvo como principales protagonistas a los empleados del sector público, a los profesores, a los estudiantes universitarios y a los trabajadores de la escindida CTCH. Efectivamente, tras una serie de movilizaciones parciales en torno a demandas salariales y de rechazo a la política antiinflacionaria de los gobiernos de la época, se avanzó hacia la formación de una Comisión Nacional de Unidad Sindical, que preparó las condiciones políticas y orgánicas que permitieron la fundación de la Central Unica de Trabajadores (en adelante, CUT), en febrero de 1953. La CUT definió con

14. Este tema se encuentra ampliamente tratado en GARCÉS, Mario, Tomando su sitio. El movimiento de pobladores de Santiago, 1957-1970, LOM Ediciones, Santiago de Chile, 2002.

15. Ver, al respecto, DRAKE, Paul, Socialismo y populismo. Chile, 1936-1973, Universidad Católica de Valparaíso, Valparaíso, 1992, pp. 189-274 y FURCI, Carmelo, El Partido Comunista de Chile..., Op. Cit., pp. 53-78. claridad la necesidad de abolir el régimen capitalista para avanzar hacia la sociedad sin clases, reivindicó la lucha de clases como método de acción política y se asumió como un organismo clasista e independiente. ${ }^{16}$

La CUT, bajo el liderazgo del dirigente de la Agrupación Nacional de Empleados Fiscales (ANEF), Clotario Blest Riffo, jugó, a partir de este momento, un rol clave en el proceso de reanimación del movimiento de masas y en el desarrollo de la lucha social. Expresión de ello fue una creciente tendencia a la sindicalización de la clase trabajadora, la que a fines de la década de 1960 llegaba prácticamente al millón de obreros sindicalizados. De la misma manera se puede observar un desarrollo sostenido de la politización al interior de los trabajadores, proceso que los vinculaba claramente con las organizaciones de la izquierda. Por último, se puede apreciar también, el uso sistemático de la huelga general y de la paralización de actividades, tanto para demandar una mejora en las condiciones laborales de los trabajadores, como para denunciar un atropello, abuso o actitud represiva, tanto de los patrones como del Estado. ${ }^{17}$

16. CUT, Declaración de principios y estatutos, Central Única de Trabajadores de Chile, CUT, Santiago de Chile, 1970, pp. 1-2; GARCÉS, Mario y MILOS, Pedro, FOCH, CTCH, CUT. Las centrales unitarias en la historia del sindicalismo chileno, ECO, Santiago de Chile, 1988, pp. 100-103; BLEST, Clotario, "La CUT y los partidos políticos” (1957), en SALINAS, Maximiliano, Clotario Blest, Arzobispado de Santiago, Vicaría de la Pastoral Obrera, Santiago de Chile, 1980, pp. 198211; y BARRÍA, Jorge, Historia de la CUT, Prensa Latinoamericana, Santiago de Chile, 1971, pp. 37-84.

17. GARCÉS, Mario y MILOS, Pedro, FOCH..., Op. Cit., pp. 104-115. 
Este proceso de rearme ideológico y político de la clase obrera impactó profundamente en el Partido Socialista (en adelante, PS). Efectivamente, el PS, tras la crisis interna que derivó en la fractura de la organización en dos referentes (el PSCh y el Partido Socialista Popular), producida al calor de los debates críticos y autocríticos sobre la experiencia de la colaboración de clases frente-populista (1947), inició un sostenido proceso de discusión interno que maduró en la propuesta de "Frente de Trabajadores". De acuerdo con esta propuesta, adoptada en 1955, el PS debía convertirse en "una fuerte organización popular de carácter revolucionario, que sirva de instrumento de lucha para la toma del poder primero, y el estado revolucionario después". ${ }^{18}$ En concordancia con esta definición le correspondía al PS unir a todas las fuerzas, políticas y sociales, dispuestas a poner fin al régimen capitalista. Este nuevo planteamiento cerró la puerta a toda nueva experiencia de colaboración de clases y favoreció la creación, en 1956, del Frente de Acción Popular (en adelante, FRAP). Más tarde (1957, 1959, 1961 y 1964), el PS reafirmó en sus congresos ordinarios ésta estrategia política y, en virtud de ello, el FRAP presentó un programa de transformaciones revolucionarias (nacionalización de las riquezas básicas, de la banca y de los grandes complejos industriales, reforma agraria $y$ política internacional independiente), y una candidatura propia (Salvador Allende), a las elecciones presidenciales de 1958 y 1964.

Tras la aplastante derrota electoral de la izquierda, frente a la Democracia Cristiana (en adelante, DC) en las elecciones presidenciales

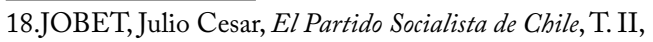
Prensa Latinoamericana, Santiago de Chile, 1971, p. 20. de 1964, y fuertemente tensionado por su ala izquierdista, el PS descartó la vía electoral (Congreso General Ordinario de 1965), como método para la conquista del poder. No obstante lo anterior, también se indicó que los mecanismos electorales continuaban prestando utilidad como herramientas de movilización de masas.

Esta postura fue posteriormente ratificada en el XXII Congreso General ordinario del PS, realizado en la ciudad de Chillán, entre los días 24 y 26 de noviembre de 1967. En esa oportunidad los socialistas chilenos aprobaron un voto político que en sus aspectos centrales establecía que la violencia revolucionaria era "inevitable y legítima" en todo proceso de lucha por el poder. ${ }^{19}$

Las temáticas de la conquista del poder y de la utilización de la violencia política como instrumento para alcanzarlo, se convirtieron en elementos vertebradores de la propuesta política del campo revolucionario. En ello, no cabe duda, las tesis leninistas, por una parte, y el modelo revolucionario cubano, por la otra, se transformaron en los soportes teóricos y políticos de los nuevos diseños que se adoptaron. ${ }^{20}$

Hacia 1965, el proceso de radicalización experimentado por el movimiento popular presentaba varias vertientes. Se manifestaba a través del ascenso de las luchas obreras,

19. PARTIDO SOCIALISTA DE CHILE, "Voto sobre la posición política nacional adoptado en el XXII Congreso Nacional Ordinario, Chillán, 24 al 26 de noviembre de 1967", en JOBET, Julio Cesar, El Partido Socialista de Chile, T. II, p. 130.

20. Ver, MARINI, Ruy Mauro, Subdesarrollo y revolución, Siglo XXI Editores, México, 1969 y GARCÍA, Cecilio, Revolución Cubana: Historia, conflictos y desafios, Editorial Escaparate, Concepción, 2012. 
del surgimiento de nuevos actores sociales (pobladores) y de la acelerada puesta en escena del campesinado. Tenía que ver también con la definición de un camino propio por parte de la izquierda chilena, al interior de la cual el PS se revelaba como la organización más radicalizada. También se hacía cada vez más evidente la influencia teórica, política y moral de la revolución cubana. Por último, remitía a la existencia de una serie de organizaciones y grupos que aspiraban a transformar el escenario político a través de la formación de una organización revolucionaria que se pusiera a la cabeza del movimiento de masas, en la lucha por la construcción del socialismo.

\section{Poder y revolución en el pensamiento de la izquierda revolucionaria chilena}

No cabe duda que la denominada "Nueva Izquierda Latinoamericana" de la década de 1960, encontró en la Revolución Cubana su principal influencia teórica. Es más, se puede llegar a establecer que la teoría del foco guerrillero, desarrollada por Ernesto Che Guevara, se convirtió en su principal contribución. No obstante, no todos los movimientos insurgentes del período se inspiraron, de forma exclusiva, en el modelo cubano. Para muchos de estos movimientos, entre los que contamos al Movimiento de Izquierda Revolucionaria chileno (en adelante, MIR), la teoría leninista del partido revolucionario y de la toma del poder por la vanguardia revolucionaria, continuó siendo el referente ideológico más importante. Por ende, la caracterización de la sociedad, de las relaciones de poder y del rol y función del movimiento social revolucionario y de la vanguardia del proletariado, encuen- tran su soporte teórico en este paradigma. No es extraño, por lo tanto, encontrar permanentes alusiones a los clásicos del marxismo en los documentos del MIR.

Un elemento central en la teoría revolucionaria refiere al Estado y a las relaciones de poder que se construyen al interior de la sociedad. Federico Engels, sostenía al respecto (1884), que la institucionalidad estatal, es un producto de la sociedad cuando esta llega a un grado de desarrollo determinado. Es la confesión de que esa sociedad se ha enredado en una irremediable contradicción consigo misma y está dividida por antagonismos irreconciliables, que no logra conjurar. ${ }^{21}$ De esta manera el Estado surge como un poder llamado a establecer mecanismos de orden que amortigüen los conflictos sociales. Es por lo tanto, producto y manifestación del carácter irreconciliable de las contradicciones de clase. El Estado, entonces es reconocido por los revolucionarios como un órgano de dominación de clase; un sistema político, jurídico y punitivo que legaliza y afianza esta opresión. En un documento de 1968 Baustista van Schowen, miembro de la comisión política del MIR, señalaba:

La dominación de la burguesía se basa en la violencia burguesa (el Estado)... la violencia para el explotado es un hecho diario, constatable fácilmente, presente diariamente en su vida es aquella violencia ejercida a través de la explotación, a través del trabajo que desarrolla el explotado en la infraestructura, en la base económica del régimen burgués... Una sociedad estructurada de esta forma, basada en una pugna de intereses, en una lucha de clases tendría, lógicamente un destino: el aplastamiento

21. ENGELS, Federico, El origen de la familia, la propiedad privada y el Estado, Editorial Claridad, Buenos Aires, 1941. 
de la minoría y por ende, el triunfo de los intereses de la mayoría, la creación de una nueva sociedad que respondiera al sentir de los más. ${ }^{22}$

Por su parte Vladímir Ilich Ulianov, Lenin, sostuvo que la liberación de las clases oprimidas sólo era posible mediante una revolución violenta que involucrara la destrucción del aparato del poder estatal que había sido creado por la clase dominante. En este contexto, el elemento central que permite la estabilidad del Estado es el monopolio de la fuerza; es decir, el ejército permanente, la policía y la política impositiva que permite sostenerlos. El rasgo distintivo de la sociedad democrática, que no invalida lo anterior, se encuentra en que el sufragio universal y los mecanismos de representación tienden a encubrir las relaciones de dominación de clase. En ambos casos la solución es el asalto y la destrucción del Estado burgués, su reemplazo por la dictadura del proletariado (el pueblo en armas) y la consecución de una sociedad sin clases, es decir, la extinción del Estado. ${ }^{23}$ Estas orientaciones ya se encontraban contenidas en las tesis político-militares presentadas por Miguel Enríquez Espinoza (quien sería desde 1967 y hasta su muerte en 1974, el principal líder del MIR), al congreso fundacional de 1965. En ese documento Enríquez sostuvo que sus planteamientos tenían como referentes a Clausewitz, Marx, Engels, Lenin y Trotsky, así como las experiencias de la Revolución Rusa, Cubana y China y los

22. VAN SCHOWEN, Bautista, "Estrategia insurreccional, 1968”, en HERNÁNDEZ, Martín, El pensamiento revolucionario de Bautista van Schowen, 1943-1973, Ediciones Escaparate, Concepción, 2004, pp. 99-100.

23. LENIN, El Estado y la revolución, Ediciones en Lenguas Extranjeras, Pekín, 1975 [1918]. procesos insurreccionales contemporáneos de Venezuela y Perú. ${ }^{24}$ Más adelante, Enríquez caracterizó los principales modelos estratégicos utilizados por los revolucionarios; tanto el urbano insurreccional, triunfante en Rusia en 1917, como el de lucha guerrillera rural, desarrollado en China, Vietnam y Cuba. Es importante consignar, en este punto, que la adscripción de la tendencia guevarista (liderada por Enríquez), por el modelo revolucionario cubano era profunda. De esta manera, al rendir un homenaje a la Revolución Cubana, en julio de 1973, el dirigente del MIR Bautista van Schowen destacó:

Queremos rendir un homenaje a una revolución de verdad; a una revolución que en el transcurso de su camino resolvió los problemas fundamentales de toda revolución. Una revolución que resolvió el problema del poder, problema esencial a cualquier proceso revolucionario... Rendimos homenaje a una revolución que al tiempo de andar definiera su carácter como revolución socialista y proletaria. Rendimos homenaje a una revolución que ha ido resolviendo el problema de la conducción de las masas y de la correcta relación entre su vanguardia revolucionaria y el conjunto del pueblo. ${ }^{25}$

No es extraño, por lo tanto, que las tesis de 1965 señalen con precisión que ese modelo, la estrategia de guerra popular, desplegada por guerrillas rurales, era el más pertinente para la

\footnotetext{
24. MIR, “Tesis político-militar, 1965”, en ALVAREZ, Marco, La constituyente revolucionaria. Historia de la fundación del MIR chileno, LOM Ediciones, Santiago de Chile, 2015, p. 145.
}

25. VAN SCHOWEN, "Bautista, Rendimos homenaje...”, Op. Cit., p. 223. 
consecución del triunfo revolucionario. ${ }^{26} \mathrm{No}$ obstante lo anterior, el MIR no reivindicaba a la guerrilla como el instrumento de conducción del proceso revolucionario, marcando con ello un distanciamiento respecto del modelo cubano; sino que colocaba en el centro de dicho proceso al partido revolucionario.

E1 MIR se organiza para ser la vanguardia marxista-leninista de la clase obrera y capas oprimidas de Chile que buscan la emancipación nacional y social. El MIR se considera el auténtico heredero de las tradiciones revolucionarias chilenas y el continuador de la trayectoria socialista de Luis Emilio Recabarren, el líder del proletariado chileno. La finalidad del MIR es el derrocamiento del sistema capitalista y su reemplazo por un gobierno de obreros y campesinos, dirigidos por los órganos del poder proletario, cuya tarea será construir el socialismo y extinguir gradualmente el Estado hasta llegar a la sociedad sin clases. La destrucción del capitalismo implica un enfrentamiento revolucionario de las clases antagónicas. ${ }^{27}$

Inmersos en esta vorágine de discusiones teóricas y políticas, los revolucionarios arribaron a la década de 1960. Época decisivamente marcada por el desarrollo de movimientos de liberación nacional en América Latina, África y Asia; movimiento que, con las armas en la mano, demostraban la capacidad de los pobresy explotados del mundo de liberarse de las cadenas de la dominación, tanto criollas como imperialistas. ${ }^{28}$ Así, los

26. MIR, “Tesis político-militar”, 1965, pp. 154-156.

27. MIR, Declaración de principios, Santiago de Chile, septiembre de 1965, p. 2.

28. Ver al respecto: HOUSER, George M., "Assesing Africa's liberation struggle", en Africa Today, Indianapolis, 1987, V. 34, No 4, pp. 17-32 y KUSHNER, Barak, escritos del dirigente revolucionario argelino Frantz Fanon, tuvieron un fuerte impacto en la conceptualización estratégica mirista, especialmente en el análisis y proyección de las formas de lucha insurreccionales. ${ }^{29}$ Por su parte, los escritos político-militares de Vo Nguyen Giap, pusieron de relieve el carácter de guerra popular prolongada que adquirían los modernos enfrentamientos antiimperialistas. ${ }^{30}$

\section{Contexto y escenario de la fundación del MIR}

Una vez concluida la Segunda Guerra Mundial, la situación política internacional quedó definida por el enfrentamiento a escala global entre el campo capitalista, dirigido por EE.UU., y el campo socialista, encabezado por la Unión Soviética. ${ }^{31}$ Efectivamente, la acentuación de los conflictos en este período (Medio Oriente, Corea, Sudeste Asiático y África del Norte), produjo cambios profundos en el orden políticos global y en la correlación de fuerzas entre los bandos en disputa.

Se intensificaron los procesos de descolonización tanto en África como

"Treacherous allies: The Cold War in East Asia and American postwar anxiety", en Journal of Contemporary History, London, 2010, V. 45, No 4, pp. 812-843.

29. FANON, Frantz, Los condenados de la tierra, Fondo de Cultura Económica, México, 1965.

30. GIAP, Vo Nguyen, Guerra de liberación, Editorial Quimantú, Santiago de Chile, 1972 y GIAP, Vo Nguyen, El hombre y el arma, Ediciones La Rosa Blindada, Buenos Aires, 1968.

31. Un estudio general sobre el fenómeno en BURLEIGH, Michael, Pequeñas guerras, lugares remotos (insurrección global y la génesis del mundo moderno), Taurus, Madrid, 2014. 
en Asia, situación que influyó de manera importante en la formación de la nueva izquierda o izquierda revolucionaria de la década de $1960 .^{32} \mathrm{El}$ surgimiento de estos movimientos de liberación nacional ofreció nuevas alternativas para la construcción de un programa revolucionario (anticapitalismo y antiimperialismo) e instaló la sublevación armada como un modelo de acción política (Revolución China, Revolución Vietnamita, Revolución Argelina). Se trataba de un fenómeno nuevo que se desarrollaba precisamente en países en los cuales el capitalismo, como sistema económico, no había alcanzado su plena madurez. Lo anterior cuestionaba, en buenas medida las teorías estructuralistas del marxismo, que suponían que los procesos revolucionarios tenían que darse en primer lugar en los países de capitalismo avanzado. Los movimientos de liberación nacional y los procesos de descolonización obligaron a los intelectuales revolucionarios a reflexionar sobre nuevos modelos y diseños a objeto de comprender e intervenir de mejor forma en este tipo de situaciones. $^{33}$

No cabe duda que uno de los fenómenos políticos que alcanzó mayor incidencia a escala regional fue la Revolución Cubana. Efectivamente, la toma del poder en Cuba por el Movimiento 26 de Julio, en 1959,

32. Estos procesos han sido analizados en: BESSIS, Sophie, Occidente y los otros. Historia de una supremacia, Alianza, Madrid, 2002.

33. Estos intelectuales y militantes políticos, profundamente comprometidos con los cambios revolucionarios, adquirieron gran notoriedad en América Latina y sus trabajos (en especial las síntesis de su pensamiento político), circularon ampliamente en la región. Entre los más conocidos habría que señalar a Ernesto "Che" Guevara, Frantz Fanon, Ho Chi Min, Patrice Lumumba, Kwame Nkrumha y Vo Nguyen Giap. y el posterior proceso de construcción del socialismo de la década de 1960, se transformaron en un desafío teórico y político para el conjunto de la izquierda a escala global. La divulgación de los contenidos y de la experiencia de la Revolución Cubana durante la década de 1960 le otorgó sentido y contenido al andamiaje teórico y político de los movimientos insurgentes. ${ }^{34} \mathrm{Al}$ respecto, un documento del MIR de julio de 1971 señalaba:

La Revolución Cubana es revolución, y la saludamos hoy aquí, porque golpeó implacablemente a los dueños del poder y la riqueza y porque puso ese poder y riqueza al servicio de los intereses de los trabajadores del campo y la ciudad. La Revolución Cubana, es revolución porque golpeó, denunció, destruyó y aplastó el poder norteamericano en Cuba. Es revolución porque comprendió que no se pueden hacer revoluciones hoy en el mundo sin entrar a enfrentar y combatir al imperialismo norteamericano. ${ }^{35}$

La Revolución Cubana adquiría relevancia ante los líderes revolucionarios locales por la envergadura del proceso político protagonizado, por la mística que

34. Los debates políticos e intelectuales sobre la revolución encontraron en la revista cubana Pensamiento Crítico (1967-1971), una de las tribunas privilegiadas para su desarrollo y divulgación. En Chile la Revista Punto Final (1965-1973) y posteriormente la Revista Chile Hoy (1972-1973), reprodujeron parte importante de esas discusiones o los escritos de sus protagonistas. Por otro lado, el texto de Lenin, El Estado y la revolución (1918) y los trabajos de Ernesto "Che" Guevara, Guerra de guerrillas (1960) y el Diario del Che en Bolivia (1967), formaron parte de acervo básico de los militantes revolucionarios latinoamericanos.

35. ENRÍQUEZ, Miguel, "Hay que crear una nueva legalidad", en Punto Final, Santiago de Chile, 03/08/1971, p. 30. 
acompañaba el quehacer de las vanguardias y por la proximidad temporal y espacial del fenómeno. Pero, por otro lado, la intensificación de los enfrentamientos sociales durante la década de 1960 permitió visibilizar a nuevos actores político-sociales en el escenario latinoamericano. De esta manera se produjo una revalorización de los movimientos campesino, indígena, de pobladores y estudiantil; movimientos que, hasta ese momento, habían constituido categorías secundarias en la construcción del movimiento social revolucionario. La visión escolástica del marxismo, predominante en las ciencias sociales y en las organizaciones políticas de la época, reivindicaba exclusivamente al proletariado como clase revolucionaria. No obstante, en los países de capitalismo periférico, como eran los de América Latina, los protagonistas de las revoluciones del siglo XX, en México (1917), Bolivia (1952) y Cuba (1959), habían sido el campesinado y los indígenas. ${ }^{36}$ Estos aspectos, propios de la composición social de las sociedades latinoamericanas, se convirtieron en elementos centrales del análisis sobre las estrategias de poder y respecto de la fuerza social revolucionaria.

Como señalamos previamente, en este mismo período se produjeron profundos cambios en la sociedad chilena: la extensión del modelo de acumulación basado en el patrón sustitutivo de importaciones; la amplia y sostenida migración campo-ciudad, que densificó la

36. DE LA PEÑA, Guillermo, "Las movilizaciones rurales en América Latina desde c. 1920, en BETHELL, Leslie (editor) Historia de América Latina. Política y sociedad desde 1930, V. 12, Crítica, Barcelona, 1997, pp. 193-280 y FEDER, Ernest, Violencia y despojo del campesino: Latifundismo y explotación, Siglo XXI Editores, México, 1978, pp. 173-262. pobreza en los principales centros urbanos; y el reagrupamiento y radicalización de la izquierda social y política. Pero ese punto de inflexión no significó necesariamente una readecuación de los lineamientos tácticos al interior de la izquierda. Por el contrario, el escenario político electoral continuó siendo el espacio priorizado por la izquierda chilena. Pero las discusiones en torno al problema de la conquista del poder provocaron, desde fines de la década de 1950, una serie de escisiones y expulsiones de militantes tanto en el Partido Comunista, como en el Partido Socialista.

En este contexto, las pequeñas organizaciones revolucionarias existentes en Chile desde fines de la década de 1930 y los militantes escindidos o expulsados de los partidos tradicionales, fueron configurando escenarios de encuentro y discusión. De esta manera, el Comité de Solidaridad con la Revolución Cubana, creado por Clotario Blest en 1961, permitió la concurrencia de trotskistas, maoístas, cristianos revolucionarios y castristas. Al calor de estas experiencias unitarias y de los debates políticos que se precipitaron en su interior, estas organizaciones iniciaron un lento y complejo proceso de unidad política. A él concurrieron el Movimiento 3 de Noviembre, fundado por Clotario Blest en 1961; el Partido Obrero revolucionario (1937), de orientación trotskista; los anarcosindicalistas dirigidos por Ernesto Miranda, afiliados en el Movimiento Libertario 7 de Julio (1957); y los militantes comunistas dirigidos por Luis Reinoso, expulsado del Partido Comunista en 1949, y que a comienzos de la década de 1960 formaban parte del Movimiento de Resistencia Antiimperialista. El eje vertebrador de este proceso unitario fue la Vanguardia Revolucionaria Marxista (1963), compuesta mayoritariamente por ex militantes 
del Partido y de la Juventud Socialista, que para 1964 se había convertido en el principal referente revolucionario en Chile. ${ }^{37}$ Ese año, previo a la constitución del MIR, esta organización apelaba a la formación de una nueva organización revolucionaria en Chile:

Decimos a los trabajadores de todo Chile y a nuestros compañeros de base del Partido Socialista, que seguimos fieles a la bandera marxista-leninista desplegada por nosotros en el interior del Partido y en las luchas callejeras y huelguistas.

Al romper públicamente con el Partido Socialista, nos sumamos a una vasta marea que lucha por restaurar la pureza revolucionaria del marxismo frente a la traición abierta del REVISIONISMO, adueñado de las directivas del Partido Socialista y del Partido Comunista.

Creemos que urge agrupar a todos los militantes socialistas y comunistas que buscan en Chile, bajo el común denominador del marxismo-leninismo y de una abierta lucha contra el revisionismo oportunista, la organización de una Vanguardia Revolucionaria Proletaria dispuesta a dirigir la Revolución chilena. ${ }^{38}$

La derrota electoral sufrida por la izquierda en las elecciones presidenciales de 1964 generó un nuevo y más profundo debate al interior del campo popular. Las estrategias electoralistas

37. Cf. PALIERAKI, Eugenia, ¡La revolución ya viene! El MIR chileno en los años sesenta, LOM Ediciones, Santiago de Chile, 2014, pp. 10-95; ALVAREZ, Marco, La constituyente..., Op. Cit., pp. 55-68 y GOICOVIC, Igor, Trabajadores al poder. El MIR y el proyecto revolucionario en Chile, 1965-1994, Ediciones Escaparate, Concepción, 2016, pp. 107-114.

\section{VANGUARDIA REVOLUCIONARIA}

MARXISTA, Insurrección socialista, Santiago de Chile, 1964, p. 3.

90 demostraron, una vez más, sus insuficiencias y debilidades y abrieron un nuevo flanco al desarrollo de las posturas revolucionarias. Las aguas entre la izquierda tradicional y las organizaciones revolucionarias, se separaron definitivamente. La brecha que se abrió permitió que los sectores aglutinados en torno al polo revolucionario dieran el paso necesario para formar la vanguardia de la revolución chilena. Ese hito se produjo el 15 de agosto de 1965 con la fundación del MIR.

\section{El diseño estratégico en la fase pre-revolucionaria}

En 1965 el MIR era una organización heterogénea, en la cual predominaba una conducción de carácter trotskista, liderada por el médico Enrique Sepúlveda, que intentaba filiar a la nueva organización con los planteamientos revolucionarios clásicos, derivados de su profunda adscripción a la Revolución Bolchevique. No obstante, la principal fuerza disidente, compuesta por el núcleo de estudiantes universitarios prevenientes de Concepción y liderados por el médico Miguel Enríquez, presionaban por asignarle un carácter más claramente guevarista a la organización. ${ }^{39}$ Pese a las profundas discrepancias entre ambos grupos, el MIR logró construir un consenso programático; en él se sostenía que el MIR nacía para convertirse en la vanguardia marxista-leninista de la clase obrera y de las capas oprimidas de Chile, a la vez que se concebía como el heredero histórico de las

39. VITALE, Luis, Contribución a la historia del MIR (1965-1970), Ediciones del Instituto de Investigación de Movimientos Sociales Pedro Vuskovic, Santiago de Chile, 1999, pp. 8-12. 
tradiciones revolucionarias chilenas. En esta perspectiva la finalidad del MIR era derrocar el sistema capitalista y reemplazarlo por un gobierno de obreros y campesinos, dirigido por los órganos del poder proletario, fijándose como tarea la construcción del socialismo y la extinción gradual del Estado, hasta llegar a la sociedad sin clases. El MIR reconocía la existencia histórica de la lucha de clases y, de acuerdo con ello, asumía el combate intransigente contra los explotadores, rechazando todo intento de amortiguar esa lucha. Se planteaba, además, que el siglo XX era la etapa de agonía definitiva del sistema capitalista. ${ }^{40}$

Para el MIR la burguesía chilena había demostrado su incapacidad para resolver las tareas democrático-burguesas (liberación nacional, reforma agraria, liquidación de los vestigios semifeudales, etc.). Este hecho ponía al descubierto la inexistencia de una ilusoria "burguesía progresista" y, por consiguiente, se rechazaba la teoría de la revolución por etapas y la política de colaboración de clases asumida por la izquierda tradicional chilena desde fines de la década de 1930. Más adelante el MIR denunciaba las tácticas políticas utilizadas por la izquierda tradicional, en particular la lucha por reformar el sistema capitalista, el electoralismo, el abandono de la acción directa, la vía pacífica y parlamentaria al socialismo, etc. Para el MIR estos lineamientos confundían, defraudaban y desarmaban al proletariado. El MIR planteaba como único camino para derrocar el régimen capitalista: la insurrección popular armada. Precisamente, uno de las contribuciones teóricas y estratégicas más importantes del

40. MIR, Declaración de principios, p. 2.
MIR al pensamiento revolucionario en Chile, fue la introducción de las formas armadas de lucha como estrategia de enfrentamiento con el Estado y las clases dominantes. ${ }^{41}$

En el Tercer Congreso del MIR, realizado en la ciudad de Santiago en el mes de diciembre del año 1967, el sector castrista, liderado por Miguel Enríquez, Bautista Van Schowen, Luciano Cruz y Andrés Pascal, conquistó la mayoría del comité central (10 cargos de 15), los cinco cargos del secretariado nacional y la secretaría general del partido (Miguel Enríquez). ${ }^{42}$ A partir de este momento, se diseñó un nuevo modelo organizacional. Se conformaron los grupos político-militares, que eran estructuras orgánicas intermedias que articulaban bases de masas, operativas y de técnicas e infraestructura (redes de apoyo). En concordancia con lo anterior, la política de reclutamiento se hizo más rigurosa, aplicándose criterios de selectividad en la perspectiva de construir un partido de cuadros y, al mismo tiempo, se comenzó a desarrollar una política de acciones armadas (principalmente asaltos a instituciones financieras), que apuntaban a foguear a las unidades especiales y a desarrollar la estructura de aseguramientos.

En el plano de masas se aprovechó la agudización experimentada por la lucha de

41. CERDA, Luis y TORRES, Ignacio, "La visión estratégica del Che y Miguel sobre la revolución latinoamericana”, en NARANJO, Pedro (coordinador) Miguel Enríquez. Páginas de historia y lucha, Centro de Estudios Miguel Enríquez (CEME), Estocolmo, 1999, p. 22. Una visión duramente crítica de este enfoque se encuentra en VIDAL, Hernán, Presencia del MIR. 14 claves existenciales, Mosquito Editores, Santiago de Chile, 1999.

42. VITALE, Luis, Contribución a la historia del MIR..., Op. Ciт.., PP. I 7-25. 
clases en el período y la coyuntura electoral de 1970, que llevó al gobierno a Salvador Allende y a la coalición de centro-izquierda Unidad Popular (en adelante, UP), para penetrar en los sectores más radicalizados del movimiento popular. El MIR entendía que el triunfo electoral de septiembre de 1970 se debía transformar en una oportunidad política para avanzar hacia la conquista efectiva del poder.

Sostenemos que la mayoría electoral de la izquierda o un gobierno de la UP son un excelente punto de partida para la lucha directa por la conquista del poder por los trabajadores, que incorporando nuevos contingentes de masas y bajo nuevas formas de lucha, con seguridad terminará en un enfrentamiento entre los explotadores nacionales y extranjeros por un lado y los trabajadores por el otro... Consecuentemente el MIR se propone apoyar esas medidas [Programa de la UP], empujar la realización de ese programa, buscar su radicalización en los frentes de masas, y hoy, como tarea fundamental y urgente, colocar sus esfuerzos en la defensa del triunfo electoral, frente ala maquinación de la derecha y el imperialismo. ${ }^{43}$

Lo anterior, a juicio de la dirección del MIR, no cuestionaba la centralidad estratégica de la lucha armada en la conquista del poder, pero si obligaba a realizar ajustes tácticos a la estrategia del mirismo. Se partía del supuesto general de la capacidad y disposición a la resistencia manifestada por la burguesía chilena frente a las medidas anticapitalistas

43. MIR, "Declaración pública: El MIR a los obreros, campesinos, pobladores, estudiantes y soldados, septiembre de 1970", en RADRIGAN, Cecilia y ORTEGA, Miriam (compiladoras) Miguel Enríquez: Con vista a la esperanza, Ediciones Escaparate, Santiago de Chile, 1998, p. 44.

92 adoptadas por el gobierno de la UP. Ello ponía de relieve, a juicio del MIR, los alcances y radicalidad de la lucha de clases en el país. De acuerdo con esto, la guerra revolucionaria irregular y prolongada propuesta por el MIR entraba en una fase de acumulación de fuerzas que debía desembocar, inexorablemente, en el enfrentamiento armado entre los diferentes bloques en pugna. En ese sentido el escenario abierto por el triunfo electoral de la UP relevaba otros espacios de acumulación, como la acción directa (ocupaciones de fábricas, predios agrícolas y terrenos urbanos), la movilización de las masas en el espacio público (mítines y concentraciones) y la lucha callejera. ${ }^{44}$

En concordancia con estos planteamientos se articuló una línea de frentes intermedios (Frente de Trabajadores Revolucionarios, FTR; Movimiento Universitario de Izquierda, MUI; Frente de Estudiantes Revolucionarios, FER; Movimiento Campesino Revolucionario, MCR; y el Movimiento de Pobladores Revolucionarios, MPR), destinados a sistematizar las demandas populares y a conducir sus luchas. ${ }^{45}$

44. MIR, "El MIR y el resultado electoral, octubre de 1970", en Punto Final, 13/10/1970, pp. 6-7. Este planteamiento llevó al MIR a criticar las acciones armadas de la Vanguardia Organizada del Pueblo (VOP); grupo de ultraizquierda que en junio de 1971 asesinó al ex ministro del interior de Eduardo Frei Montalva, el DC, Edmundo Pérez Zujovic. Ver al respecto MIR, "Declaración pública: El MIR a los obreros, estudiantes y soldados, 16 de junio de 1971", en RADRIGAN, Cecilia y ORTEGA, Miriam (compiladoras) Miguel Enríquez: Con vista..., Op. Cit., p. 73.

45. Ver, MIR, "Algunos antecedentes del Movimiento de Izquierda Revolucionaria (MIR), marzo de 1970", en RADRIGAN, Cecilia y ORTEGA, Miriam (compiladoras) Miguel Enríquez: Con vista..., Op. Cit., p. 70 y NARANJO, Pedro, Miguel Enríquez..., Op. Cit., p. 14. 
En este plano se experimentó un crecimiento cualitativo entre los trabajadores textiles y del carbón, y en los sectores estudiantil, poblacional y de campesinos mapuches. ${ }^{46}$ Al finalizar esta etapa el MIR había logrado decantar su estructura orgánica, conseguido implementar las tareas básicas contempladas en sus definiciones estratégicas (partido de cuadros y accionar armado) y consolidarse como organización en el plano nacional, con una influencia creciente entre los sectores más activos del movimiento de masas.

Durante todo el período de la UP el MIR insistió en la inevitabilidad del enfrentamiento armado, en consonancia con ello se planteaba la construcción de una fuerza social revolucionaria, que fuera capaz de crear una nueva situación política y, a partir de ello, la construcción de una nueva legalidad, como único camino para resolver el problema del poder. De esta manera, la consigna del "poder popular” adquirió una dimensión estratégica, en cuanto cristalizó como una manifestación paralela al Estado burgués, asentado en las organizaciones y fuerzas sociales autónomas del proletariado y el pueblo. ${ }^{47}$

Las elecciones parlamentarias desarrolladas en Chile en marzo de 1973 demostraron que la UP contaba con un respaldo del

46. MIR, "Informe al comité central sobre las conversaciones del MIR y la UP, mayo de 1972”, en RADRIGAN, Cecilia y ORTEGA, Miriam (compiladoras) Miguel Enríquez: Con vista..., Op. Cit., p. 140 .

47. GRAMEGNA, Marco Antonio y ROJAS, Gloria, "La izquierda revolucionaria en la lucha política e ideológica actual”, en Marxismo y Revolución, Santiago de Chile, julio-septiembre de 1973, № 1, p. 144 y CANCINO, Hugo, Chile: la problemática del poder popular en el proceso de la vía chilena al socialismo, 1970-1973, Aarhus University Press, Aarhus, 1988, pp. 321-430
44\% del electorado. Con ello, la opción de la oposición (DC y Partido Nacional), de precipitar la renuncia de Salvador Allende a la jefatura del Estado se vio obturada, ya que dicho procedimiento sólo era posible estando en posesión de $2 / 3$ de la representación parlamentaria. Lo anterior acentúo la crisis política que se venía desarrollando desde agosto de 1972 y abrió el camino tanto a la asonada golpista, como a la ruptura revolucionaria. A ese efecto el MIR planteaba en mayo de 1973:

La tarea política fundamental planteada hoy, a la clase obrera y al pueblo, es pasar a una posición esencialmente ofensiva frente a la arremetida patronal en desarrollo. Es acumular la fuerza de mansas necesarias para impedir o ganar la guerra civil, si los patrones o sectores reaccionarios deciden desatarla; para impedir la capitulación reformista frente al peligro de la guerra civil, y para conquistar posiciones decisivas en la lucha por la conquista del poder para la clase obrera y sus aliados, imponiendo un verdadero Gobierno de Trabajadores.

Este proceso de acumulación de fuerzas persigue la constitución de un bloque social revolucionario, donde la clase obrera dirija socialmente a los pobres de la ciudad, del campo y a la pequeña burguesía, y reconozca como su conducción a una alianza política en la cual los revolucionarios y los sectores radicalizados de la izquierda sean predominantes..$^{48}$

En este plano, las crisis de poder se debía resolver, necesariamente, a través del enfrentamiento armado, el cual se concebía,

48. MIR, "Resoluciones sobre la situación política nacional, mayo de 1973”, en RADRIGAN, Cecilia y ORTEGA, Miriam (compiladoras) Miguel Enríquez: Con vista..., Op. Cit., pp. 256-257. 
a comienzos de la década de 1970, como una "guerra revolucionaria irregular y prolongada". En esta perspectiva la línea de construcción de la fuerza social revolucionaria apuntaba a ganar la conducción del movimiento de masas, para lo cual resultaba imprescindible insertarse en los frentes sociales e incentivar las formas rupturistas de lucha; construir una institucionalidad paralela, en la que el gobierno de la UP y sus políticas debían contribuir a radicalizar el proceso; desarrollar la fuerza militar propia, sobre la base de núcleos orgánicos especializados, masa armada y penetración en el aparato militar del Estado; y radicalizar las posiciones revolucionarias al interior de los partidos de la UP. ${ }^{49}$

Hacia 1973 el MIR, producto de su análisis de la situación política nacional y de la evaluación de sus rangos de inserción y conducción en y sobre el movimiento de masas, concluía que sólo existían dos caminos para el desarrollo de la lucha de clases en Chile: la capitulación reformista frente a las presiones de la burguesía (devolución de empresas tomadas y convocatoria a un plebiscito para dirimir el conflicto político) o la contraofensiva revolucionaria. Si esta última desencadenaba el Golpe de Estado se creía que se contaba con la fuerza necesaria para aplastarlo.

Pese a la apreciación anterior la respuesta del movimiento de masas y del MIR al Golpe de Estado del 11 de septiembre de 1973 no fue la esperada. El movimiento de masas desconcertado, golpeado y fragmentado permaneció en su mayor parte pasivo, atemorizado y no desarrolló resistencia;

49. Ídem, pp. 253-257. mientras que los sectores de vanguardia en los barrios industriales, en poblaciones y en algunas zonas rurales, que ocuparon sus frentes de lucha a la espera de conducción y armamento, fueron posteriormente desalojados y violentamente reprimidos. ${ }^{50} \mathrm{En}$ todo caso el balance inmediato realizado por el MIR diagnosticaba que la estrategia que había fracasado en Chile era la del reformismo, no así la estrategia revolucionaria, la que si bien quedaba expuesta al reflujo y retroceso experimentado por la lucha popular, aparecía legitimada política y moralmente por cuanto se planteaba como única alternativa para retomar la conducción del proceso revolucionario en Chile. ${ }^{51}$

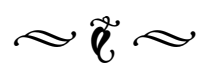

Recibido: 08-02-2017 Aceptado: 04-08-2017 Publicado: 05-12-2017

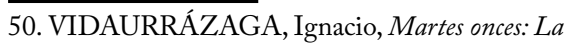
primera resistencia, LOM Ediciones, Santiago de Chile, 2013.

51. MIR, "La táctica del MIR en el actual período, diciembre de 1973”, en RADRIGAN, Cecilia y ORTEGA, Miriam (compiladoras) Miguel Enríquez: Con vista..., Op. Cit., pp. 293-328. 


\section{Bibliografía}

ARTAZA, Pablo, Movimiento social y politización popular en Tarapacá: 1900-1912, Ediciones Escaparate, Santiago, 2006.

BARRÍA, Jorge, Historia de la CUT, Prensa Latinoamericana, Santiago de Chile, 1971.

BESSIS, Sophie, Occidente y los otros. Historia de una supremacía, Alianza, Madrid, 2002.

BLEST, Clotario, "La CUT y los partidos políticos" (1957), en SALINAS, Maximiliano, Clotario Blest, Arzobispado de Santiago, Vicaría de la Pastoral Obrera, Santiago de Chile, 1980.

BURLEIGH, Michael, Pequeñas guerras, lugares remotos (insurrección global y la génesis del mundo moderno), Taurus, Madrid, 2014.

CANCINO, Hugo, Chile: la problemática del poder popular en el proceso de la vía chilena al socialismo, 19701973, Aarhus University Press, Aarhus, 1988.

CERDA, Luis y TORRES, Ignacio, "La visión estratégica del Che y Miguel sobre la revolución latinoamericana”, en NARANJO, Pedro (coordinador) Miguel Enríquez. Páginas de historia y lucha, Centro de Estudios Miguel Enríquez (CEME), Estocolmo, 1999.

CUT, Declaración de principios y estatutos, Central Única de Trabajadores de Chile, CUT, Santiago de Chile, 1970.

DE LA PEÑA, Guillermo, "Las movilizaciones rurales en América Latina desde c. 1920, en BETHELL, Leslie (editor) Historia de América Latina. Politica y sociedad desde 1930, V. 12, Crítica, Barcelona, 1997, pp. 193-280.

DESHAZO, Peter, Trabajadores urbanos y sindicatos en Chile: 1902-1927, Centro de Investigaciones Diego Barros Arana - DIBAM, Santiago de Chile, 2007.

DRAKE, Paul, Socialismo y populismo. Chile, 1936-1973, Universidad Católica de Valparaíso, Valparaíso, 1992.

ENGELS, Federico, El origen de la familia, la propiedad privada y el Estado, Editorial Claridad, Buenos Aires, 1941.

ENRÍQUEZ, Miguel, “Hay que crear una nueva legalidad”, en Punto Final, Santiago de Chile, 03/08/1971.

FANON, Frantz, Los condenados de la tierra, Fondo de Cultura Económica, México, 1965.

FEDER, Ernest, Violencia y despojo del campesino: Latifundismo y explotación, Siglo XXI Editores, México, 1978.

FURCI, Carmelo, El Partido Comunista de Chile y la vía al socialismo, Ariadna Editores, Santiago de Chile, 2008. 
GARCÉS, Mario y MILOS, Pedro, FOCH, CTCH, CUT. Las centrales unitarias en la historia del sindicalismo chileno, ECO, Santiago de Chile, 1988.

GARCÉS, Mario, Tomando su sitio. El movimiento de pobladores de Santiago, 1957-1970, LOM Ediciones, Santiago de Chile, 2002.

GARCÍA, Cecilio, Revolución Cubana: Historia, conflictos y desafíos, Editorial Escaparate, Concepción, 2012.

GIAP, Vo Nguyen, El hombre y el arma, Ediciones La Rosa Blindada, Buenos Aires, 1968.

GIAP, Vo Nguyen, Guerra de liberación, Editorial Quimantú, Santiago de Chile, 1972.

GOICOVIC, Igor, Trabajadores al poder. El MIR y el proyecto revolucionario en Chile, 1965-1994, Ediciones Escaparate, Concepción, 2016.

GRAMEGNA, Marco Antonio y ROJAS, Gloria, "La izquierda revolucionaria en la lucha política e ideológica actual”, en Marxismo y Revolución, Santiago de Chile, julio-septiembre de 1973, No 1.

GREZ, Sergio, Historia del comunismo en Chile. La era de Recabarren (1912-1924), LOM Ediciones, Santiago de Chile, 2011.

GREZ, Sergio, Los anarquistas y el movimiento obrero: La alborada de la idea en Chile, 1893-1915, LOM Ediciones, Santiago de Chile, 2007.

HOUSER, George M., “Assesing Africa's liberation struggle”, en Africa Today, Indianapolis, 1987, V. 34, No 4, pp. 17-32.

JOBET, Julio Cesar, El partido Socialista de Chile, T. I y II, Editorial PLA, Santiago de Chile, 1971.

KUSHNER, Barak, "Treacherous allies: The Cold War in East Asia and American postwar anxiety", en Journal of Contemporary History, London, 2010, V. 45, No 4, pp. 812-843.

LENIN, El Estado y la revolución, Ediciones en Lenguas Extranjeras, Pekín, 1975 [1918].

MARINI, Ruy Mauro, Subdesarrollo y revolución, Siglo XXI Editores, México, 1969.

MELLER, Patricio, Un siglo de economía politica chilena (1890-1990), Editorial Andrés Bello, Santiago de Chile, 1998.

MILOS, Pedro, Frente Popular en Chile: Su configuración, 1935-1938, LOM Ediciones, Santiago de Chile, 2008.

MIR, “Algunos antecedentes del Movimiento de Izquierda Revolucionaria (MIR), marzo de 1970”, en RADRIGAN, Cecilia y ORTEGA, Miriam (compiladoras) Miguel Enríquez: Con vista a la esperanza, Ediciones Escaparate, Santiago de Chile, 1998.

MIR, "Declaración pública: El MIR a los obreros, campesinos, pobladores, estudiantes y soldados, septiem- 
bre de 1970”, en RADRIGAN, Cecilia y ORTEGA, Miriam (compiladoras) Miguel Enríquez: Con vista a la esperanza, Ediciones Escaparate, Santiago de Chile, 1998.

MIR, “Declaración pública: El MIR a los obreros, estudiantes y soldados, 16 de junio de 1971”, RADRIGAN, Cecilia y ORTEGA, Miriam (compiladoras) Miguel Enriquez: Con vista a la esperanza, Ediciones Escaparate, Santiago de Chile, 1998.

MIR, “Informe al comité central sobre las conversaciones del MIR y la UP, mayo de 1972", en en RADRIGAN, Cecilia y ORTEGA, Miriam (compiladoras) Miguel Enriquez: Con vista a la esperanza, Ediciones Escaparate, Santiago de Chile, 1998.

MIR, “La táctica del MIR en el actual período, diciembre de 1973”, en RADRIGAN, Cecilia y ORTEGA, Miriam (compiladoras) Miguel Enríquez: Con vista a la esperanza, Ediciones Escaparate, Santiago de Chile, 1998.

MIR, “Resoluciones sobre la situación política nacional, mayo de 1973”, en RADRIGAN, Cecilia y ORTEGA, Miriam (compiladoras) Miguel Enríquez: Con vista a la esperanza, Ediciones Escaparate, Santiago de Chile, 1998.

MIR, “Tesis político-militar, 1965”, en ALVAREZ, Marco, La constituyente revolucionaria. Historia de la fundación del MIR chileno, LOM Ediciones, Santiago de Chile, 2015.

MIR, Declaración de principios, Santiago de Chile, septiembre de 1965.

MIR, “E1 MIR y el resultado electoral, octubre de 1970”, en Punto Final,13/10/1970, pp. 6-7.

MUNDLAK, Yair, “Migración del campo a la ciudad: Análisis empírico basado en datos rurales”, en Cuadernos de Economía, Santiago de Chile, 1978, V.15, No 45, pp. 143-181.

NARANJO, Pedro, "Semblanza biográfica y política de Miguel Enríquez", en NARANJO, Pedro (coordinador) Miguel Enríquez. Páginas de historia y lucha, Centro de Estudios Miguel Enríquez (CEME), Estocolmo, 1999.

PALIERAKI, Eugenia, ¡La revolución ya viene! El MIR chileno en los años sesenta, LOM Ediciones, Santiago de Chile, 2014.

PARTIDO SOCIALISTA DE CHILE, "Voto sobre la posición política nacional adoptado en el XXII Congreso Nacional Ordinario, Chillán, 24 al 26 de noviembre de 1967”, en JOBET, Julio Cesar, El Partido Socialista de Chile, T. II.

PINTO, Julio, Luis Emilio Recabarren. Una biografía histórica, LOM Ediciones, Santiago de Chile, 2013.

PINTO, Julio, Trabajos y rebeldias en la pampa salitrera, Ediciones Universidad de Santigo de Chile, Santiago de Chile, 2012.

RAMIREZ, Hernán, Origen y formación del Partido Comunista de Chile, Editorial Progreso, Moscú, 1984. 
RECABARREN Luis Emilio, La Rusia obrera y campesina, La Federación Obrera, Santiago de Chile, 1923.

VAN SCHOWEN, “Bautista, Rendimos homenaje a una revolución para hacer la revolución, 1973”, en HERNÁNDEZ, Martín, El pensamiento revolucionario de Bautista van Schorven, 1943-1973, Ediciones Escaparate, Concepción, 2004.

VAN SCHOWEN, Bautista, “Estrategia insurreccional, 1968”, en HERNÁNDEZ, Martín, El pensamiento revolucionario de Bautista van Schowen, 1943-1973, Ediciones Escaparate, Concepción, 2004.

VANGUARDIA REVOLUCIONARIA MARXISTA, Insurrección socialista, Santiago de Chile, 1964.

VIDAL, Hernán, Presencia del MIR. 14 claves existenciales, Mosquito Editores, Santiago de Chile, 1999.

VIDAURRÁZAGA, Ignacio, Martes onces: La primera resistencia, LOM Ediciones, Santiago de Chile, 2013.

VITALE, Luis, Contribución a la historia del MIR (1965-1970), Ediciones del Instituto de Investigación de Movimientos Sociales Pedro Vuskovic, Santiago de Chile, 1999.

ZEMELMAN, Hugo, El migrante rural, ICIRA, Santiago de Chile, 1971. 